\title{
A insônia do corpo priápico
}

\section{Maria Elisa Pessoa Labaki}

Este livro reúne a tradução dos trabalhos publicados em L'hypocondrie, Monographies de la Revue Française de Psychanalyse. Além destes, inclui o trabalho de Maria Helena Fernandes, "A hipocondria do sonho e o silêncio dos órgãos: o corpo na clínica psicanalítica”.

Se a psicanálise subverte a racionalidade cartesiana, é porque inaugura nova lógica para velhas oposições. Desaloja territórios conceituais redesenhando seus limites. Pares como somático-psíquico, eu-não eu, dentro-fora, sujeito-objeto etc., perdem a substancialidade de sua ordenação determinista. Apesar de ter múltiplas faces, a hipocondria pode ser considerada um protótipo de tal ruptura. Inequivocamente, é no interior da definição freudiana de pulsão que encontramos a chave psíquica para o seu substrato somático. $\mathrm{Na}$ qualidade de um autêntico modelo da concepção de conceito-limite, a hipocondria desfaz fronteiras e cria novas configurações. Atesta-se que, em algum ponto entre corpo e psique, onde o pensamento se converte em órgão de autoconservação, a hipocondria é a projeção de uma teorização psíquica a respeito do somático. Assim, seus investimentos de órgão reproduzem, do ponto de vista da 
R E V I S T A

excitação, a erogenidade dos genitais e de outras zonas erógenas, e revelam que o corpo desempenha, simultaneamente, as funções de objeto, fonte e limite da sexualização. Estes são apenas alguns dos motes que fundamentam as exposições inovadoras e originais deste livro. Nele, os autores arriscam.

Se o ensaio de Alain Fine poderia inaugurar os trabalhos desta coletânea, dada a diversidade de autores que apresenta, é, (in)justamente, devido a este mesmo mérito que o leitor menos preparado conceitualmente poderá encontrar obstáculos para trafegar fluentemente por posições conceituais tão variadas. De Freud a Fédida, passando por M. Klein e pelos kleinianos P. Heimann e H. Rosenfeld, sem contar os contemporâneos do freudismo - Tausk, Ferenczi e Federn - entre outros, Fine delimita seu campo psicopatológico sem, no entanto, abrir mão da polissemia do termo hipocondria. Tampouco se furta a enfrentar a impossibilidade de classificá-lo em um quadro nosológico específico. Psicose, neurose, síndrome ou preocupação?

Compreender sua natureza, trabalho interno e efeitos. Será que se trata dos mesmos fenômenos, da mesma organização do eu, de seus limites, de toda organização psicossomática, de quando se evoca a hipocondria do sonho, a premonição hipocondríaca, o discreto recurso hipocondríaco, por exemplo, ou as formas pesadas da hipocondria? (p. 58)

Eis algumas das indagações que balizaram a escolha de Fine em articular, na sua exposição e visitação a tantos autores, a hipocondria, tal como Freud a deixou esboçada, com outras figuras psicopatológicas, outras conceituações e novas propostas. O movimento que dá início a este ensaio de revisão destaca, assim, os dois tempos da concepção da hipocondria em Freud. O primeiro, em que aparece classificada como uma neurose atual, deixa assinalada uma diferença diagnóstica essencial, tanto em relação à histeria de conversão quanto em relação à melancolia. Depois, com a introdução do narcisismo e à luz da teoria pendular da libido de objeto versus libido do eu, surge reformulada enquanto modalidade de retirada da libido dos objetos do mundo externo sobre o eu e sobre o órgão que ocupa (análoga à doença orgânica). Daí, apenas um pequeno passo para Freud revelar um paralelismo entre a hipocondria e as categorias da parafrenia e da paranóia, no que tange aos processos de investimento sobre o eu da libido liberada nos processos de recalcamento ou onde houve outro impedimento de realização pela frustração. "Freud faz, assim, da hipocondria, o primeiro tempo do delírio e a liga a um processo patológico no quadro das patologias narcísicas relativas ao corpo" (p. 63). Cada um dos outros autores lembrados por Fine contribuiu, a sua maneira, para preencher, ao menos em parte, os espaços vazios deixados por Freud: o confronto entre hipocondria, segunda teoria das pulsões e masoquismo erógeno; bem como o desenvolvimento da reflexão sobre sua 
similaridade com os processos da melancolia. Nesta, a consciência é má; na outra, é o corpo mau.

Neste ensaio, dos mais interessantes, Georges Pragier nos apresenta um autêntico trabalho metapsicológico acerca da hipocondria. No estilo "vale quanto pesa”, encontramos neste condensado trabalho autoral aportes preciosos de autores como A. Green, M. Fain e V. Tausk, para citar apenas aqueles cujas idéias mais instigaram o autor ao diálogo. Para além do título, cabe falar em metapsicologia, dada a natureza metonímica e metafórica da abordagem conceitual. Mas não só. Ao trançar o universo da clínica, inserindo vinhetas ilustrativas, com o conceitual, o autor recria um campo de figuração e representação passível de sofrer os mesmos efeitos que o processo psíquico primário imprime ao material inconsciente: deslocamento e condensação. Curiosamente, mas não à-toa, vemos como tais operações também impregnam os mecanismos específicos da hipocondria, fazendo do órgão hipocondríaco recruta do eu "na expressão deslocada do sofrimento que limita a desorganização" (p. 86). Não se trata, portanto, de uma avaria no corpo, mas é dentro dele, nos interstícios do órgão hipocondríaco e doloroso, que a recusa da ausência do objeto vai ser representada, presentificada. É sabido que a capacidade de introjetar no eu o objeto materno perdido depende da qualidade da identificação primária. Investimento excessivo, ambíguo ou tênue, má qualidade do pára-excitação, carência da triangulação, são alguns dos "defeitos" cujos efeitos patológicos encontram na hipocondria uma forma de solução. Circuito longo e cheio de percalços, este que a pulsão desenha entre a recusa da perda do objeto e a manifestação do sintoma hipocondríaco. Seja este mera preocupação ansiosa ou uma forma de delírio. Assim, são os processos e mecanismos desta trajetória pulsional de desinvestimento do objeto, por um lado, e recuperação do objeto pelo investimento do orgão hipocondríaco, por outro, que o autor nos apresenta. Insatisfeito, porém, com as dificuldades que os conceitos de projeção, clivagem, limites do eu e auto-erotismo trazem para a construção de um modelo coerente da hipocondria, é com Green que Pragier se alivia. Complementando o que já se conhece acerca da ação da projeção no corpo (Tausk), primeiro objeto exterior, ele recorre à concepção de alucinação negativa para esclarecer o mecanismo de transformação a partir do qual o hipocondríaco identifica "o orgão doente com o objeto mau, cuja perda recusa” (p. 84). Parafraseando a formulação de Freud sobre o delírio, na hipocondria o que foi abolido fora volta para dentro. Isto é, se o corpo ocupou o lugar do objeto, do mundo externo,

... o órgão hipocondríaco representa o negativo do auto-erotismo, o ponto de ruptura da alucinação negativa da mãe, onde o corpo que tinha tomado o lugar que esta ocupava primitivamente, desfazendo a interiorização desta 
R E V I S T A

LATINOAMERICANA

DE PSICOPATOLOGIA

F U N D A M E N TA L

ano $\mathrm{VI}$, n. 2 , jun/2003

exterioridade, restabelece sua presença, ou melhor, a do objeto, cuja ausência era sinal de sua localização fora da criança (p. 101).

A hipocondria resultaria da falência do mecanismo de apagamento da mãe pela alucinação negativa, necessária para o auto-erotismo. A todo o momento, portanto, o orgão investido lembra que a mãe, de fato, não está mais lá, no sítio original. Mas, sim, no lugar deixado vago pelo auto-erotismo, ativo e prazeroso, que não se instalou. E, para complicar, sem desempenhar seu papel enquadrante que manteria o silêncio habitual e tranqüilizador do corpo (Fain), fundo sobre o qual normalmente se efetua o trabalho psíquico.

O inconsciente é esotérico? Pergunta estranha que insiste em se repetir ao longo das leituras plurais exigidas pelo texto que Fédida dedica à hipocondria. Talvez porque a influência de Ferenczi, claramente explicitada, traz a marca do recurso à imaginação de analogias fantásticas, no interior de cujas operações semânticas são relacionados termos os mais distantes entre si. O longo, mas rápido, circuito analógico deve partir de uma associação que instaura a "imagem súbita” em sua eficácia imediata de produzir sentidos. E o poder da palavra será exercido no seu limite sempre que conseguir dizer mais do que pretendia. Se, neste artigo, a palavra é coisa ou, pelo menos, é tratada como tal, pode-se afirmar que a natureza do mesmo possui a envergadura textual do sonho. Mas Fédida, aqui, não narra seu sonho. Ele o sonha mesmo a céu aberto, levando consigo o leitor. E para aqueles que, como nós, querem transmiti-lo, fica a dificuldade de assim proceder sem submeter o mosaico que forma suas idéias e imagens a uma tradução simplificadora. Embora seja este, também, um dos inevitáveis destinos que o trabalho de interpretação imprime à elaboração onírica que precede o sonho. Assim, conta-se um sonho... Entre melancolia e paranóia, o hipocondríaco vive no corpo as vicissitudes de um luto desconhecido, obstruído. Efeito do autoerotismo que não se instalou, dada a intrusividade do corpo materno. Apesar de identificado com o morto, não é exatamente de melancolia que sofre o hipocondríaco, pois, ao contrário da cadaverização psíquica melancólica, na hipocondria o psiquismo é investido e erogenizado pelo órgão dolorido. Também não se trata de uma forma de paranóia, já que, diferente de atacar o órgão, a autocracia do pensamento hipocondríaco o conserva. Esta inversão denuncia a ação de defesas disparadas contra ameaças de aniquilamento pressentidas sempre que for compreendida a possibilidade de a queixa que envolve o órgão hipocondríaco ser alterada por uma influência exercida psiquicamente - do médico, do analista. A hipocondria testemunha, assim, uma sobreposição do autoerotismo à autoconservação, resultante da necessidade vital de manutenção do erotismo frente às ameaças terríveis que o psiquismo representa como força de desorganização, de decomposição e de morte. Esta duplicidade faz tal justaposição 
consistir, sobretudo, em uma forma de subversão da excitabilidade natural dos órgãos para um regime rígido de vigilância autoconservativa. Estado de alerta em relação ao qual podemos associar, analogicamente, a figura da vitalidade dolorosa do órgão priápico. Outras ressonâncias da hipocondria, como as observadas nos processos transferenciais, são trabalhadas por Fédida, que avança em relação à posição de Freud. Enfatiza os efeitos da constituição de um tipo de relação especular do hipocondríaco com o corpo do analista, cujos mecanismos pressupõem, de um lado, a denegação da pessoa deste e, de outro, a impossibilidade de ausentificação do mesmo pela alucinação negativa. Até o fim, a diversidade de imagens e formulações originais convida o leitor a acompanhar o autor nesta produção onírica e metapsicológica.

É seguindo as pistas de Freud relativas à construção do corpo pulsional que o artigo de Maria Helena Fernandes desenha seus eixos metodológicos. A constatação de que o diagnóstico de uma doença orgânica pode ser antecedido, em certos pacientes, por uma ausência completa de percepção de sinais somáticos levou a autora a se interessar pelos processos que participam da representação e percepção do corpo enquanto objeto psíquico. Propõe que a instalação da capacidade erógena do corpo, pelos investimentos libidinais do objeto (mãe) e do próprio sujeito, está na base da constituição da atividade perceptiva. Assim, o "silêncio dos órgãos", como metaforizou Fernandes em relação a esses casos em que se constata a ausência de percepção do indício somático mórbido, denuncia que "a experiência do corpo parece ter ficado ancorada no registro da necessidade, num tempo anterior ao auto-erotismo" (p. 189). Supõe, portanto, a falência da erogenidade e, conseqüentemente, dos registros auto: do prazer, da percepção, da dor. A autora nos alerta, porém, para uma distinção importante entre o fenômeno acima descrito e outro, que envolve a recusa (Verleugnung) dos sinais referentes ao processo mórbido. Neste outro, o acento recai sobre a atividade defensiva, que o sujeito aciona diante do desprazer, de desmentir as próprias percepções, negligenciando, então, as expressões do seu corpo. Uma experiência em que o corpo mostra, mas não é visto, fala, mas não é escutado. Enfim, do ponto de vista da clínica, trata-se de conhecer as modalidades de escuta do corpo, suas vibrações mais sutis, das mais altas às mais baixas freqüências. E, também, de abrir um sítio, no "espaço de um entre”, em ritmo de esconde-emostra e de vaivém (Fort-Da), onde a situação analítica possa tomar (o) corpo e fazer do mudo, ruidoso. Maria Helena brinda o leitor com um texto cristalino, sob cujo desenvolvimento teórico é possível enxergar as rotas metodológicas por onde encaminha suas hipóteses e interrogações. Não obstante a complexidade do campo e do problema em questão, o leitor escuta com nitidez os meandros dos pensamentos da autora. No texto, no divã, o trabalho da hipocondria empresta sua potência expressiva. 
R E V I S T A

Marilia Aisenstein e Alain Gibeault partem, em seus respectivos ensaios, da hipótese que formularam conjuntamente em um artigo de 1990 intitulado “O trabalho da hipocondria”. Para eles, a angústia hipocondríaca corresponderia a um processo de tentativa de ligação somatopsíquica cuja função de defesa, ou sinal, alertaria o eu em relação a um perigo na sua esfera narcísica. Nos dois ensaios em questão, os autores não só trabalham a partir desta mesma hipótese, como desenvolvem, cada um a seu estilo, uma reflexão clínica que levanta uma problemática semelhante. Trata-se de enfatizar a necessidade de abrir uma brecha, no espaço transferencial, para o investimento masoquista hipocondríaco do corpo, análogo ao investimento pelo objeto-mãe do desprazer das primeiras experiências de satisfação. Aisenstein nos conta o drama de uma mulher de 53 anos, que nunca se sentiu escutada, considerada, em relação a sua aflição hipocondríaca. Somente quando seu corpo expôs a miséria mastectomizada e devorada pela quimioterapia, é que foi encaminhada para psicoterapia. Tarde demais. Quinze anos de queixa sem eco, ao longo dos quais a paciente procurou, em vão, especialistas para detecção precoce do câncer mamário que pressentia em vias de nascer. Ilustrando com o material das duas únicas sessões que aconteceram, nas quais a paciente pode, em certa medida, reconstruir sua história edípica e seus lutos mal-elaborados, a autora se interroga sobre a legitimidade de imaginar que a doença da paciente poderia ter sido evitada caso tivesse encontrado um lugar onde falar sobre seus seios, sua feminilidade, sua maternidade. Ou seja, em casos como este, adverte-nos sobre a importância da consideração objetal nos mesmos moldes do investimento mãe-bebê de tipo hipocondríaco, cujas elaborações oferecem um destino ao desamparo. No desenvolvimento teórico que privilegia a concepção metapsicológica da pulsão, traçado tanto por Aisenstein quanto por Gibeault, a hipótese do masoquismo primário figura como importante operador conceitual por meio do qual o "trabalho da hipocondria participa dos processos de simbolização do corpo e do mundo no psiquismo" (p. 127). Toda essa concepção acerca da função do masoquismo é, a rigor, tributária da noção de dor. No inaugural "Projeto" e em trabalhos mais recentes, Freud concebeu a noção de dor como elemento fundamental para a atividade mental da representação. O que leva, por conseqüência, a considerar a economia do masoquismo essencial para o processo histórico de construção da representação do corpo no psiquismo. Se, na primeira leitura, os dois ensaios parecem irmãos siameses, dado às semelhanças que abrigam, o estudo mais atento aponta suas diferenças. Gibeault vai além e inclui o problema da elaboração da bissexualidade, a passividade e a feminilidade. "Se a angústia hipocondríaca se faz, às vezes, tão visível em suas manifestações mais patológicas, pode-se pensar que ela é uma defesa contra o terror do que está escondido - 'o continente negro' - na mulher” (p. 126). 
No artigo de Marie-Rose Moro sofremos um pouco com a indistinção em relação à terminologia utilizada. Etnopsiquiatria em alguns momentos, etnopsicanálise noutros, o fato é que, apesar dos esclarecimentos da autora, os termos surgem como sinônimos. No cerne do trabalho temos uma comovente descrição do processo terapêutico de um imigrante argelino que sofre, no corpo dolorido e na mente desmemoriada, as conseqüências traumáticas do desamparo da situação migratória, recrudescidas após um acidente de trabalho. Partindo do princípio metodológico do complementarismo (Devereux), a etnopsicanálise/ etnopsiquiatria é uma abordagem que se apóia sobre "dois discursos obrigatórios e não simultâneos, o da psicanálise e o da antropologia, considerados complementares” (p. 161). Não se reduz à fusão de duas disciplinas, nem tampouco à consideração simultânea das mesmas. Curiosidade à parte, nos lembra a autora que esta metodologia foi inspirada na noção de complementaridade enunciada por Bohr - físico, parceiro de Heisenberg na formulação da teoria da complementaridade e no desenvolvimento da teoria decorrente da relatividade, e antagonista deste no tumultuado processo de descoberta e construção da bomba atômica. Mas é, sobretudo, do ponto de vista da técnica que este movimento de descentramento dos discursos, psicanalítico e antropológico, pode ser realizado. Um setting psicoterápico "mestiçado", como descreve Moro, composto de um grupo de co-terapeutas de origens culturais e lingüísticas variadas, permite considerar a alteridade cultural do paciente migrante, suas representações culturais, bem como, a passagem da língua materna a outra. Neste contexto, a terapia recai sobre o traumatismo da perda do quadro cultural interno do sujeito desencadeado pela ruptura do quadro cultural externo que o ato migratório ocasiona. Co-construir, paciente e psicanalistas, a partir da dimensão cultural, um sentido individual para o sofrimento. Aliás, falando em migração, bem que essa proposta poderia ser transmigrada para nossos serviços públicos e beneficiar nossos migrantes vindos desses Brasis!

Encontramos no texto de Angelo Hesnard, de 1930, uma comunicação clínica cujas edificações recebem do concreto freudiano, cimento original, a liga teórica necessária à argumentação sobre as hipóteses psicopatológicas que subjazem aos dois estudos de caso apresentados. Impossível, ao ler este trabalho, não lembrar dos artigos de Freud "Neurose e psicose" e "A perda da realidade na neurose e na psicose". No entanto, o que o autor exibe ao leitor, a partir de uma minuciosa e impressionante descrição fenomenológica dos sintomas mórbidos, é menos uma explanação sobre a diferença de forças em jogo nas psicoses e nas neuroses, e mais uma interpretação do conteúdo dos delírios hipocondríacos à luz de mecanismos de regressão à situação edípica infantil e a seus derivados sádicos. Aqui, a miserabilidade do corpo permite apenas que o sonho encene seu transbordar para dentro do narcisismo que erogeniza todo o 
R E V I S T A

LATINOAMERICANA

DE PSICOPATOLOGIA

F U N D A M E T T L

ano $\mathrm{VI}$, n. 2, jun/2003

organismo, ainda que ao preço do desinvestimento da sexualidade genital, da feminilidade adulta. Paralisias, ausência de sensibilidade, alimentos que apodrecem no estômago, músculos que relaxam, urina e sangue menstrual que se misturam, coluna vertebral partida, pele ressequida, vulva envelhecida. Sentimentos de desonra moral e vazio que acompanham tal perturbação do equilíbrio erotogênico revelam a ação de "uma castração efetiva, total, com transferência da função sexual para as regiões não-genitais do organismo” (p. 25). Enfim, este artigo de 1930 é uma relíquia que nos transporta para o tempo das apresentações de doentes em cujos palcos didáticos se exercia a arte da exposição espetacular.

Para completar, temos o artigo de Colette Guedeney e Catherine Weisbrot que discorre sobre a história da hipocondria na medicina antiga, filosofia, psiquiatria e psicanálise. E, no fim do livro, uma bibliografia sobre hipocondria, reunida por Alan Fine, testemunha a importância de produzir e acumular saberes da literatura psicanalítica sobre o tema.

Pensar a hipocondria nos diversos autores contemporâneos, tendo em vista a multiplicidade de aberturas conceituais apresentadas, e inacabadas, por Freud, assemelha-se a uma visão caleidoscópica. Cada movimento de apreensão conceitual revela um ângulo diferente, a partir do qual projetam-se questões nodais sobre a hipocondria. A (im)precisão diagnóstica e a polissemia do termo; os limites entre conversão, hipocondria e somatização; a controversa posição entre excesso ou falta de auto-erotismo, intrusão ou falta do corpo materno; a associação entre hipocondria, masoquismo e trabalho de ligação; a economia dos processos de investimento erótico de órgão; as discordâncias entre as diversas posições relativas aos processos transferenciais; a utilidade do modelo da amplificação hipocondríaca do sonho, entre outros. Enfim, a leitura deste livro ultrapassa, em muito, o exercício passivo de contemplação das novas performances em psicopatologia e clínica psicanalítica. Requer a presença ativa do leitor em mais esta enigmática criação da feiticeira. 